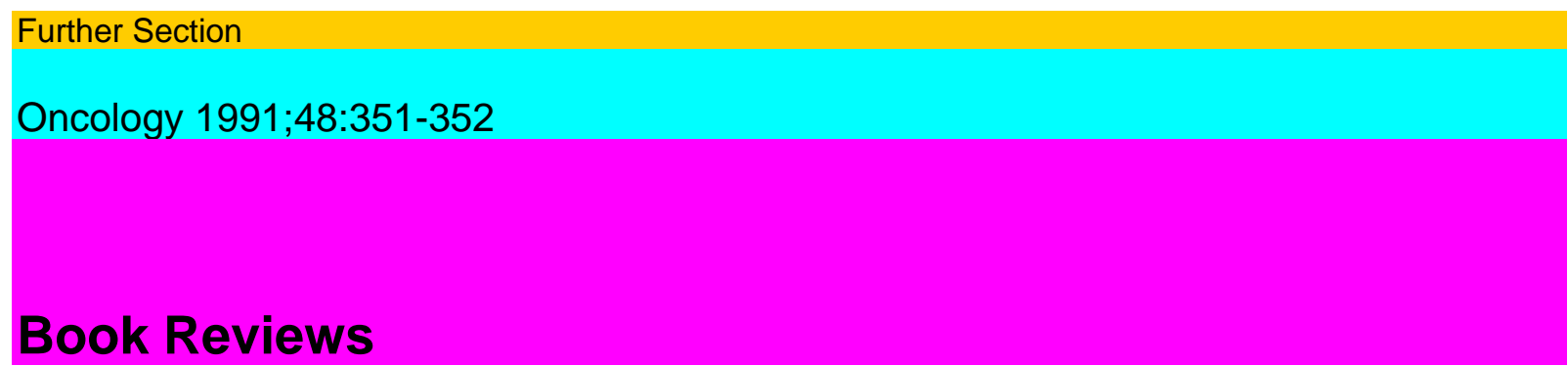

\title{
M. Kaufmann
}

Chemotherapy of Gynecological

and Breast Cancer

Karger, Basel 1987

XII + 84 pp.; SFr. 23.-/DM 28.-/USS 15.50

ISBN 3-8055-4569-X

The 3rd edition, now in English, of the small compendium on chemotherapy of gynecological and breast cancer was conceived by the authors as a working aid for physicians engaged in medical basic care, which is to provide information on general aspects, side effects, strategy and patient documentation in tumor chemotherapy. It makes use of the experience of the 'Oncological Working Circle of Heidelberg'. The book deals with general aspects of antineoplastic chemotherapy, details on hormones and cytostatics, application form of tumor chemotherapy as well as prophylaxis and treatment of cytostatic side effects. Detailed data are presented on the individual gynecological tumor localizations. The book is supplemented by suggestions on therapy judgement and documentation as well as by a list of publications in which the patient may inform himself about questions of tumor chemotherapy.

The fact that the book is now available in its 3rd edition is evidence for the positive acceptance it received. The reviewer shares this positive judgement. Of course, such concise guides to clinical practice always carry the danger that tumor chemotherapy is practiced without the necessary special knowledge. It is therefore commendable that the authors emphasize in the Preface the need for close links between basic oncological care and outpatient tumor chemotherapy in oncological centers. The reviewer wishes the book a broad audience, among whom there may be many a specialist seeking rapid and uncomplicated information about a particular problem or detail.

S. Tanneberger, Berlin-Buch

J.M. Vaeth, J.L. Meyer (eds.)

The Present and Future Role of Monoclonal

Antibodies in the Management of Cancer

Frontiers of Radiation Therapy

and Oncology, vol. 24

Karger, Basel 1990

X + 266 pp.; SFr. 254.-/DM 304.-/E 105.90

ISBN 3-8055-5029-4

This is still an experimental therapy.

With the production of monoclonal antibodies of higher specif-ity, we can expect progress in the future regarding diagnostic and therapeutic purposes. Thus will play the part of carrier molecules for isotopes or cytostatics. Experts say that until these can be regularly used, there is still a lot of research to be done. These papers clearly show the actual status of this field of research. This 
book can be advised to oncologists involved in clinical and experimental research and radiooncologists.

P. Drings, Heidelberg

Charlotte Jacobs

Carcinomas of the Head and Neck

Kluwer, Dordrecht 1990

XI+ 292 pp.; Dfl. 290.-/USS 125.-/E 87.95

ISBN 0-7923-0668-6

In this multiauthor book a total number of 16 specific topics regarding carcinomas of the head and neck are reviewed under four major headings: advances in staging and primary treatment, rehabilitation, advances in medical management and chemotherapeutic approaches and basic biology and etiology. Most of the chapters are well written and extensive lists of references are provided. However, these are not very up-to-date.

This book is of interest to all those who are involved in the diagnosis and treatment of patients with head and neck cancer, although the price appears pretty high.

G.B. Snow, Amsterdam

M. Ghione, L. Rausa (eds) Resistance to Antitumor Agents

Laboratory and Clinical Studies Ettore Majorana International Life Sciences Series, vol. 7

Harwood Academic, New York IX +322 pp.; USS 51.00 ISBN 3-7186-4956-X

The book contains the papers of the 24th Cancer Symposium in San Francisco. Well-known international authors reported on the radio-immunoglobulin therapy, the transvascular transport, the release of antibodies and the tumor-associated antibodies as well as the binding of radiolabeled monoclonal antibodies in tumor tissues.

Further results showed the binding of antibodies in patients after receiving several therapies with monoclonal antibodies and the reaction of tumors to the radioimmune therapy. Some papers reported the technical problems of radio-immune therapy such as dosimetry and dosis distribution.

The first results of clinical studies on radioimmune therapy in breast carcinoma, multiform glioblastoma, B cell lymphoma, malignant lymphomas, gastrointestinal tumors and ovarian tumors were reported and discussed.

Resistance to antitumor agents and ionizing radiation is a major obstacle in the successful therapy of malignant diseases. Based on lectures given at the 'Ettore Majorana Center's 25th Course on Resistance to Antitumour Agents in the Laboratory and Clinic', this book is one of a series of interesting papers written by a few American and a large number of Italian scientists. Since the discovery of the membrane glycoproteins of the P-170 type, the MDR became the target of extensive research. Nevertheless, neoplastic cells possess several other pathways as well to overcome any cell-killing effect. The first ten chapters are devoted to list these mechanisms and the methods to overcome drug resistance. In order to study these phenomena, models are described and the role of cell kinetics, enzyme inhibitions, and the use of in vitro cell lines are discussed. Five further chapters deal with clinical approaches to cope with resistance in breast, prostate, colon, ovarium cancer and lymphomas. Finally, radioresistance and the potential use of lonida-

352

Book Reviews 
mine as a substance influencing energy metabolism is carefully analyzed. The volume is a useful source of information for both experimental and clinical oncologists.

S. Eckhardt, Budapest

Jimmie C. Holland, Robert Zittoun Psychosocial Aspects of Oncology

ESO Monographs Springer, Heidelberg 1990 VIII+ 142 pp.; 3 fig.; DM 82.-ISBN 3-540_ 51947-5

The item of this book is among the most relevant in modern oncology. The presently rising psychooncology - by no means clearly defined in terms of contents, form and size - is based upon clear findings. The book, containing knowledge gathered by internationally renowned scientists, consists of the main chapters patient care issues, psychosocial and behavioral factors in cancer risk and survival, methods of assessment in clinical practice and research, future directions for training and research. A feasible conception for the establishment of psychooncology becomes obvious, though some of the contributions certainly are too superficial. On the whole, we are confronted with an entirely new, highly relevant direction of work, with some chapters offering already widely established methodological procedures and analyses of effects. The book is highly recommendable to everybody interested in this matter.

H. Wrba. Vienna

E. Baulieu, D. T. Forman, M. Ingelman-Sundberg, el al. (eds) Ruthenium and Other NonPlatinum Metal Complexes in Cancer Chemotherapy

Progress in Clinical Biochemistry

and Medicine, vol. 10

Springer, Heidelberg 1989

IX+ 226 pp.; 99 fig.; 47 tables; DM 138.-

ISBN 3-540-51146-6

Roswell K. Boutwell, Use L. Riegel Bristol-Myers Cancer Symposia, vol. 11 The Cellular and Molecular Biology of Human Carcinogenesis

Academic Press, London 1990 XX+ 344 pp.; USS 55.00 ISBN 0-12-119655-0

I have read with great interest the book entitled: The Cellular and Molecular Biology of Human Carcinogenesis edited by R.K. Boutwell and I.L. Riegel. The book is interesting and the panel of contributors consists of very distinguished scientists in their own field. I feel that it might be useful as a reference source for researchers interested in the various topics treated. Part II is probably the most homogeneous section of the entire book and chapter 5 gives a good overview of the problems that the scientist working in the field of chemical carcinogenesis is faced with. The chapter regarding tumorigenesis by $\mathrm{N}$-nitroso compounds is particularly interesting and well organized in its general design.

The main problem of this book is represented by the fact that the material treated is quite heterogeneous, which is typical of mul-tiauthor books. However each chapter, taken on its own, gives a good example of the multifaceted aspects of tumor biology. Most of the chapters are also quite updated in their references, even though the rapid progress in the molecular biology of cancer is bound to make them obsolete shortly.

In general, I would suggest that this book is addressed especially to those interested in getting a rapid idea on the main current trends in cancer research.

S. Garattini, Milano

H. Sommerkamp, J. E. Altwein (Hrsg.) Prostatakarzinom: Spektrum der kurativen Therapie

S. Karger AG, Basel 1989

XIV+ 334 pp.; SFr. 121.-/DM 145.-/X 50.50 
The book contains the plenary lectures of a symposium on 'Ruthenium and other Non-Platinum Metal Complexes in Cancer Chemotherapy', organized by the universities of Trieste and Udine. After the remarkable results achieved worldwide with platinum-containing anticancer drugs, it is well understandable that even other metal complex compounds are intensively investigated. The book is a milestone as concerns ruthenium and titanium complexes in these international research activities.

Described by leading international experts, all aspects of the chemistry of these types of metal complexes are discussed in detail and, moreover, experimental investigations and even clinical studies (Budotitane) are reported.

The role of non-platinum metal complexes in cancer chemotherapy still needs to be defined, and further research is necessary. The book is an essential tool for all those involved in such or similar programs and both fundamental and clinical researchers will profit by reading it.

S. Tanneberger, Berlin-Buch

A. As underlined by the authors of Prostatakarzinom

this type of cancer is one of the crucial problems of urology. At present

only $15 \%$ of the patients get a curative treatment. Doubtless

early detection is an approach to improve the cure rate but only if the tumors are treated adequately. Here the fact that prostate cancer patients are mostly elderly patients plays an important role. The book summarizes the state of the art in curative prostate cancer treatment particularly evaluating both main alternatives

prostatectomy and radiotherapy. Written by international experts all aspects of curative prostate cancer management including 'staging and differentiation' are discussed. A conclusion entitled 'Local tumor control - efficacy of curative treatment'

written by the editors

completes the book. The editorial work and the translation into German were made carefully. The book is recommended to all those involved in the management of prostate cancer.

S. Tanneberger

Berlin-Buch 